\title{
LA PROHIBICIÓN PENAL DE LA HOMOSEXUALIDAD MASCULINA JUVENIL (COMENTARIO A LA SENTENCIA DEL TRIBUNAL CONSTITUCIONAL DE 4 DE ENERO DE 2011, ROL N 1683-2010)
}

\author{
Antonio Bascuñán \\ Universidad Adolfo Ibáñez
}

\begin{abstract}
Resumen: El autor analiza críticamente la sentencia del Tribunal Constitucional sobre inaplicabilidad por inconstitucionalidad del Art. 365 del Código Penal, que prohíbe el acceso carnal a una persona del mismo sexo mayor de 14 pero menor de 18 años de edad. En su crítica, sostiene la falta de fundamentos del voto de mayoría y constata un uso tendencioso $\mathrm{y}$ tergiversado de sus pretendidas fuentes. Asimismo, observa que la jurisprudencia comparada desautoriza la posición del Tribunal Constitucional por obsoleta.

Palabras clave: sodomía, autonomía sexual, discriminación por razón de orientación sexual, edad de consentimiento sexual, derechos del niño, paternalismo.
\end{abstract}

Recibido y aceptado: noviembre 2011.

Antonio Bascuñán. Abogado. Licenciado en Ciencias Jurídicas y Sociales, Universidad de Chile. Diplomado en Derecho y Ludwig-Maximilian Universität München. Profesor de Derecho Penal y Teoría del Derecho en la Universidad Adolfo Ibáñez y en la Universidad de Chile (a.bascunan@uai.cl). 


\title{
THE CRIME OF JUVENILE MALE HOMOSEXUALITY (COMMENTARY ON THE DECISION BY THE CONSTITUTIONAL COURT ON JANUARY 4, 2011, CASE \#1683-2010)
}

\begin{abstract}
The author takes a critical look at the decision by the Constitutional Court ruling that Article 365 of the Penal Code cannot be considered unconstitutional, which forbids carnal relations with a person of the same sex who is older than 14 but younger than 18 years of age. In his critique, he argues that the majority vote was not grounded and confirms a slanted and twisted use of the claimed sources. He also notes that comparative jurisprudence overrules the position of the Constitutional Court because it is obsolete.
\end{abstract}

Keywords: sodomy, sexual autonomy, discrimination on the grounds of sexual orientation, age of sexual consent, children's rights, paternalism.

Received and accepted: November 2011.

1. $\square_{n}$ su redacción conforme a la modificación introducida por la Ley 19.617 (Diario Oficial de 12 de julio de 1999), el Art. 365 del Código Penal dispone:

Art. 365. El que accediere carnalmente a un menor de dieciocho años de su mismo sexo, sin que medien las circunstancias de los delitos de violación o estupro, será penado con reclusión menor en sus grados mínimo a medio.

La interpretación contextualizada de esta disposición conduce a la conclusión de que la norma prohíbe la penetración genital anal de una persona de género masculino menor de 18 años pero mayor de 14 años, incluso si no se emplea fuerza ni intimidación; ni se halla la víctima privada de sentido; ni se aprovecha su incapacidad para oponer resistencia; ni se abusa de su enajenación o trastorno mental; ni se abusa de una anomalía o perturbación mental, aun transitoria, de la víctima, que por su menor entidad no sea constitutiva de enajenación o trastorno; ni se abusa de una relación de dependencia de la víctima, como en los casos en que el agresor está encargado de su custodia, educación o cuidado, o tiene con ella una relación laboral; ni se abusa del grave desamparo en que se encuentra la víctima; ni se la engaña abusando de su inexperien- 
cia o ignorancia sexual. En otras palabras, aunque la penetración genital no sea abusiva conforme a los criterios con que el Código Penal define los atentados sexuales contra personas mayores de 14 años, se encuentra prohibida cuando la persona penetrada genitalmente es de género masculino y no ha cumplido los 18 años $^{1}$. Si se trata, en cambio, de una persona de género femenino, la penetración genital de su vagina, ano o boca resta impune, a título de atentado sexual, cuando no es abusiva bajo esos criterios.

2. El 13 de abril de 2010 la Defensoría Penal Pública presentó ante el Tribunal Constitucional un requerimiento para declarar inaplicable por inconstitucional el Art. 365 CP en la causa RIT 1287-2008 seguida ante el Juzgado de Garantía de Cañete contra Sepúlveda Álvarez ${ }^{2}$. El requerimiento fue acogido a tramitación por resolución del 11 de mayo de 2010 y declarado admisible por resolución del 27 de mayo, con voto en contra del Ministro Francisco Fernández Fredes, quien estimó que el requerimiento carecía de fundamento plausible. El 9 de septiembre de 2010, a las 15.30 horas se procedió a la vista de la causa, alegando un abogado de la Defensoría Penal Pública por el requirente. El pleno del tribunal acordó fijar un tiempo para mayor estudio del asunto, suspendiendo el debate y el acuerdo. El 14 de octubre de 2010 la Defensora Nacional presentó ante el tribunal un informe en derecho sosteniendo la inconstitucionalidad del Art. 365 del Código Penal, elaborado por cator-

${ }^{1}$ Es usual deducir de lo anterior que el Art. 365 CP sanciona la penetración genital del ano del menor de edad incluso cuando ella es plenamente consentida por el menor. En sus propios términos, esta deducción incurre en una falacia de non sequitur: que la acción sea punible aun cuando no sea abusiva en los términos de la regulación de la violación y el estupro, no implica que no haya de ser abusiva bajo otros criterios. Sí es correcto asumir que el sentido literal posible de la disposición admite la comprensión de la norma como una prohibición incluso del acceso carnal seria y libremente consentido por el menor. Basta con eso para generar el problema de constitucionalidad que fue objeto de discusión en este caso.

${ }^{2}$ Con anterioridad a este requerimiento, la disposición legal había sido impugnada ante el tribunal en dos oportunidades, sin resultados: (i) Robert Pizarro, Rol N ${ }^{\circ}$ 1334, requerimiento de 19 febrero de 2009, declaración de inadmisibilidad de 19 de marzo del mismo año; (ii) Van den Hove, Rol N ${ }^{\circ} 1482$, requerimiento de 7 de septiembre de 2009, declaración de inadmisibilidad de 21 octubre del mismo año. 
ce profesores de derecho penal ${ }^{3}$. El 19 de octubre de 2010 el pleno del tribunal adoptó acuerdo en la causa. El 4 de enero de 2011 el tribunal dio a conocer su sentencia, en la que rechaza el requerimiento ${ }^{4}$.

El Tribunal Constitucional adoptó su acuerdo por mayoría de 6 votos; el voto de mayoría fue redactado por la Ministra Marisol Peña Torres y suscrito además por el Presidente (S), Raúl Bertelsen Repetto, y los Ministros Mario Fernández Baeza, Francisco Fernández Fredes, Iván Aróstica Maldonado y Enrique Navarro Beltrán, este último con un voto de prevención. El extenso voto disidente fue redactado y suscrito por los Ministros Hernán Vodanovic Schnacke, Carlos Carmona Salgado y José Antonio Viera-Gallo Quesney. En este lugar interesa comentar el voto de mayoría.

3. El voto de mayoría afirma como principio general una deferencia del tribunal hacia la legítima prerrogativa de decisión del legislador democrático (considerandos $18^{\circ}$ a $22^{\circ}$ ), rechaza que el Art. $365 \mathrm{CP}$ establezca una discriminación arbitraria que viole el derecho a la igualdad ante la ley (considerandos $23^{\circ}$ a $34^{\circ}$ ), rechaza que viole el derecho a la privacidad (considerandos $35^{\circ}$ a $42^{\circ}$ ) y rechaza que viole el derecho al libre desarrollo de la personalidad $\left(43^{\circ}\right.$ a $\left.52^{\circ}\right)$.

Independientemente de cuestiones relativas a la comprensión que el voto de mayoría tiene de los tres derechos considerados como parámetros de control de constitucionalidad del Art. $365 \mathrm{CP}^{5}$, es común

${ }^{3}$ Sus autores son los profesores Jaime Couso Salas (Universidad Diego Portales), Juan Pablo Cox Leixelard (Universidad Adolfo Ibáñez), Felipe De la Fuente Hulaud (Universidad Adolfo Ibáñez), José Ángel Fernández Cruz (Universidad Austral), Héctor Hernández Basualto (Universidad Diego Portales), María Inés Horvitz Lennon (Universidad de Chile), Juan Pablo Mañalich Raffo (Universidad de Chile), José Luis Guzmán Dálbora (Universidad de Valparaíso), Gonzalo Medina Schulz (Universidad de Chile), Guillermo Oliver Calderón (Pontificia Universidad Católica de Valparaíso), Luis Rodríguez Collao (Pontificia Universidad Católica de Valparaíso), Luis Emilio Rojas Aquirre (Universidad Alberto Hurtado), Miguel Soto Piñeiro (Universidad de Chile) y el suscrito. Este comentario se apoya sustancialmente en el contenido del informe.

${ }^{4}$ Las piezas del expediente se encuentran disponibles en línea en el sitio del tribunal constitucional: http://www.tribunalconstitucional.cl/index.php/rols/ view/542 (última visita: 23 de mayo de 2011).

${ }^{5}$ Que son: (i) una insostenible validación de la comprensión jurisprudencial chilena del principio de igualdad como una exigencia de tratar igual a los iguales y desigualmente a los desiguales (cons. 24); (ii) una insostenible reducción del contenido del derecho a la vida privada al manejo de información 
a todo su razonamiento sostener que la eventual afectación del ámbito prima facie protegido por cualquiera de esas normas constitucionales se encuentra en concreto justificada por el fin perseguido por el legislador mediante la prohibición establecida en esa disposición. Este fin es caracterizado así:

[E]l fin perseguido por el legislador fue la protección de la integridad física y psíquica y la indemnidad sexual de los menores de edad, entendida como la necesidad de precaver daños o perjuicios al desarrollo psicosocial de quien, por las propias circunstancias de su madurez física y emocional, no está en plenas condiciones de comprender el alcance de sus actos, sino hasta llegar a la etapa adulta. De esta forma, por mucho que la relación aparezca como consentida [...] el legislador ha entendido que dicho consentimiento prestado por un menor de 18 y mayor de 14 años de edad no puede tener el mismo alcance que el de una persona adulta, pues aquél no posee conciencia clara de los efectos, incluso físicos, que su conducta puede generar ${ }^{6}$.

Conforme al voto de mayoría, el hecho de que éste sea el fin perseguido por el legislador hace que la prohibición establecida por el Art. $365 \mathrm{CP}$ sea razonable, por lo que no constituye una discriminación arbitraria (cons. $31^{\circ}$ y $33^{\circ}$ ) y representa una limitación legal justificada tanto a la privacidad (cons. $41^{\circ}$ ) como al libre desarrollo de la personalidad (cons. $42^{\circ}$ ). Éste es, en lo esencial, el argumento del voto de mayoría.

4. En un sentido mínimo, la decisión del Tribunal Constitucional implica un logro desde una perspectiva comprometida con la defensa de la igual libertad para toda orientación sexual. El Tribunal no afirma explícitamente la constitucionalidad de la norma en virtud de su concordancia con alguna comprensión heredada de la moral social sexual que repruebe las orientaciones sexuales diversas de la heterosexualidad. Para el Tribunal, la legitimidad del Art. 365 CP ante la Constitución

(cons. $36^{\circ}$ a $38^{\circ}$ ), y (iii) un insostenible desconocimiento del derecho al libre desarrollo de la personalidad como parte del derecho a la libertad personal (cons. $44^{\circ}$ a $50^{\circ}$ ). El voto disidente refuta los tres errores del voto de mayoría: (i) cons. $18^{\circ}$ y $36^{\circ}$, (ii) cons. $49^{\circ}$ a $52^{\circ}$ y (iii) cons. $58^{\circ}$ y $59^{\circ}$. El voto de prevención contribuye a la refutación de (iii).

${ }^{6}$ Considerando $28^{\circ}$, párrafo primero. 
estaría avalada por la finalidad de prevenir un daño para el menor. En qué consista ese daño, eso no es claro. Pero al menos la sentencia se compromete con la concepción del delito en cuestión como un atentado contra una víctima y no como una infracción que en principio cometen por igual ambos partícipes ${ }^{7}$. Dicho en los términos actuales del epígrafe del título vii del libro segundo del código penal chileno, para el Tribunal la legítima finalidad de protección perseguida por el Art. 365 no es la moralidad pública sino la integridad sexual de una persona: de un hombre mayor de 14 pero menor de 18 años ${ }^{8}$.

No obstante, en los términos con que el voto de mayoría pretende justificar su decisión, el argumento del Tribunal Constitucional es una burla.

5. Nadie duda que en abstracto la protección de la vida, la salud corporal y la salud mental de los menores de edad sea un fin en sí mismo legítimo. Nadie cuestiona, tampoco, que el desarrollo de la autonomía sexual de los menores de edad pueda requerir una protección

${ }^{7}$ Esta comprensión - expresada en la redacción introducida por la Ley 19.617 - lo diferencia del delito de sodomía que el código penal chileno (1875) establecía en el inciso único de su artículo 365 hasta la Ley 17.927 (1972) y luego en su inciso primero hasta la reforma introducida por la Ley 19.617. La regulación originaria chilena se explica como una pervivencia del derecho colonial español, que en esta materia se remonta al derecho de los reyes visigodos: Fuero Juzgo, leyes 5 y 6, título vi, libro iii; Fuero Real de Alfonso X, ley 12, título ix, libro iv; Partida Séptima, título 21, ley 1; Novísima Recopilación, leyes 1 y 2, título 30, libro 12 (correspondientes a una instrucción de los Reyes Católicos de 1497 y a una pragmática de Felipe II de 1598). El uso del término "sodomía" se basa en la interpretación del pasaje bíblico de la destrucción de las ciudades de Sodoma y Gomorra (Génesis 19) como castigo de la homosexualidad de sus habitantes. Esa interpretación del pecado sodomítico es actualmente controvertida, considerándose que en el contexto del Antiguo Testamento (por ejemplo, Jueces 19, 22-30; Sabiduría 19, 13-14), ratificado por expresiones atribuidas a Jesús de Galilea en el Nuevo Testamento (Lucas 10,10-12), dicho pecado corresponde más bien a la comisión de actos violentos de maltrato a los extranjeros en violación de los deberes de hospitalidad (John Boswell, Cristianismo, Tolerancia Social y Homosexualidad, 1993, p. 115-131; Mark D. Jordan, The Invention of Sodomy in Christian Theology, 1997, p. 30-37).

${ }^{8}$ El Tribunal Constitucional asume además que esta concepción del delito avala una interpretación restrictiva de la expresión "accediere carnalmente", reduciéndola a la penetración genital del ano del menor; es decir, excluyendo la relevancia jurídico-penal de la penetración genital de su boca (considerando $16^{\circ}$ ). 
especial, más intensa que la dispensada a la autonomía sexual de los mayores de edad. La cuestión no radica, pues, en si éste es o no un fin en sí mismo legítimo, sino en el modo como el Art. 365 CP pretendidamente sirve a ese fin como medio. Pues lo hace:

(1) estableciendo un trato diferenciado respecto de toda otra acción de significación sexual con una persona menor de 18 y mayor de 14 años, y

(2) desconociendo al menos en su faz (esto es, conforme a su tenor literal) la autonomía del menor.

5.1. El Código Penal protege el desarrollo de la autonomía sexual de los menores de edad estableciendo dos estándares especiales, distintos de los criterios de protección de la autonomía sexual de los mayores de edad. Conforme a un estándar, se prohíbe prima facie absolutamente - esto es, sin sujetar la prohibición a la concurrencia de medios comisivos especificados o circunstancias especiales - la realización de acciones sexuales y la interacción de significación sexual con menores impúberes, es decir, personas menores de 14 años ${ }^{9}$. Este carácter prima facie absoluto de la prohibición se expresa en la descripción del estado de cosas que se desea asegurar como la "incolumidad", "la indemnidad" o la "intangibilidad sexual" del menor: en principio, lo que la ley pretende es protegerlos de toda acción sexual o interacción de significación sexual ${ }^{10}$. Conforme al otro estándar, se prohíbe el uso de ciertos medios o el aprovechamiento de ciertas circunstancias con ocasión de la realización de acciones sexuales y la interacción de significación sexual con menores púberes, es decir, personas menores de 18 pero mayores de 14 años. Se trata de casos de abuso menos grave que los abusos punibles por regla general, que sólo resultan punibles como abuso sexual cuando recaen en menores de edad ${ }^{11}$.

${ }^{9}$ Este estándar se consagra en los Arts. 362, 365 bis № 3, 366 bis, 366 quáter incisos primero y segundo, 366 quinquies del Código Penal.

${ }^{10} \mathrm{La}$ excepción se encuentra en las acciones de significación sexual realizadas con impúberes respecto de los cuales no existe una diferencia de edad superior a 2 años (si la acción sexual es el acceso carnal) o a 3 años (si es otra acción de significación sexual). Para estos casos, el Art. $4^{\circ}$ de la Ley 20.084 declara no procesable penalmente al joven que realiza la acción de significación sexual con el impúber.

${ }^{11}$ Este estándar se consagra en los Arts. 363, 365 bis $N^{\circ} 3,366$ inciso segundo, 366 quáter inciso tercero del Código Penal. 
La prohibición del Art. 365 sólo es aplicable a mayores de 14 años. Si son menores de esa edad, el acceso carnal es constitutivo de violación conforme al Art. 362. Luego, la protección especial al menor púber requeriría consagrarse conforme al segundo estándar, es decir, sancionándose el acceso carnal obtenido mediante abuso menos grave. Pero el Art. 363 (estupro) ya sanciona el acceso carnal al menor de 18 años en esas circunstancias. El Art. 365 cubre por lo tanto casos de acceso carnal realizado sin esas modalidades de abuso. En consecuencia, según las coordenadas del propio Código Penal el acceso carnal descrito en el Art. 365 no merecería pena: no se lo realiza con un menor impúber ni se lo realiza abusivamente ${ }^{12}$.

5.2. La diferencia de trato dada al acceso carnal homosexual masculino no sólo es relevante respecto del interés de libertad e igualdad de quien mantiene la relación sexual con el menor de edad, sino también

${ }^{12}$ La Ley 19.927 (Diario Oficial de 14 de enero de 2004) estableció dos disposiciones legales que también se desentienden de las coordenadas sistemáticas de los atentados sexuales: el Art. 366 quinquies $\mathrm{CP}$, que sanciona la participación en la producción de material pornográfico en cuya elaboración hubieren sido utilizados menores de edad, y el Art. 367 inciso primero CP, que sanciona la mera promoción o favorecimiento de la prostitución de menores, por oposición a la promoción o favorecimiento habituales, con abuso de autoridad o confianza o con engaño. En el Art. 366 quinquies el legislador confundió la prohibición de la interacción de significación sexual con un menor de edad con la prohibición de la representación sexualizada de la imagen de un menor de edad. Esa confusión se ha visto intensificada recientemente con la Ley 20.526 (Diario Oficial de 13 de agosto de 2011). Por su parte, el Art. 367 inciso primero carece de sentido una vez que se sanciona al usuario de la prostitución juvenil, como lo hizo la Ley 19.927 mediante la introducción del Art. 367 ter. Esta última disposición, que sanciona la obtención de servicios sexuales de un menor de 18 pero mayor de 14 años a cambio de dinero y otras prestaciones de cualquier naturaleza, persigue en abstracto una finalidad congruente con el sistema de los atentados sexuales, cual es, impedir la explotación del menor. No es casual que el voto de mayoría cite estas tres disposiciones como ejemplo de reglas que otorgan "una protección especial en materia de delitos sexuales" a los menores de edad (cons. $26^{\circ}$ ). Pero estas reglas no ejemplifican el sistema de protección de las personas frente a delitos de abuso sexual (consagrado por los Arts. 361 a 363 y 365 bis a 366 quáter), sino que constituyen anomalías respecto de ese sistema. Además, ninguna de esas reglas establece una diferencia por orientación sexual, como tampoco lo hace su fuente inspiradora, el Protocolo facultativo de la Convención sobre los Derechos del Niño relativo a la venta de niños, la prostitución infantil y la utilización de niños en la pornografía, de 25 de mayo de 2000. 
respecto del interés de libertad e igualdad del propio menor de edad. El voto de mayoría describe el fin de esta prohibición como "protección de la indemnidad sexual" del menor. Esto implica considerar a la persona mayor de 14 años como una persona menor de 14 años respecto de ese comportamiento. Esta infantilización del menor púber es descrita por el voto de mayoría como el hecho de entender el legislador que el consentimiento de un menor de edad es meramente aparente, porque "no puede tener el mismo alcance que el de una persona adulta"13.

Pero ¿por qué no puede tenerlo? La regulación de los atentados sexuales en el Código Penal —violación (Arts. 361, 362), estupro (Art. 363), abusos sexuales simples (Arts. 366, 366 bis) y calificados (Art. 365 bis), interacción abusiva de significación sexual (Art. 366 quáter)reconoce inequívocamente al menor púber un margen de autonomía dentro del cual su consentimiento tiene exactamente el mismo alcance que el de una persona adulta: excluye por completo la relevancia jurídico-penal de la acción de significación sexual realizada por él, con él o ante él. La razón de ello se encuentra en que la ley no asume que la abstinencia sexual hasta la mayoría de edad sea una condición necesaria para el desarrollo de la autonomía sexual. Por el contrario, la ley asume que ese desarrollo puede tener lugar mediante la adquisición de experiencia sexual antes de la mayoría de edad, con tal de que el menor no sea objeto de abuso, en un sentido más amplio que el aplicable a los mayores de edad: el sentido que corresponde al segundo estándar de protección especial arriba mencionado. La ley reconoce al menor de edad de género masculino este ámbito de autonomía para realizar toda clase de acciones de significación sexual con personas de género femenino y para realizar casi toda clase de acciones de significación sexual

${ }^{13}$ Supra, nota 5 . Contrariamente a lo que el considerando $14^{\circ}$ del voto de mayoría pretende dar a entender, esta infantilización del menor púber no es avalada por toda la doctrina chilena que en él se cita. La consideración del "desarrollo libre de perturbaciones de la autodeterminación sexual del menor" como bien jurídico protegido - defendida por el suscrito- exige concretar la perturbación en un modo abusivo de trato del menor. A su vez, la consideración del delito en cuestión como un delito de corrupción — defendida en su momento por Luis Rodríguez Collao- exige constatar que en el caso concreto el menor esté en situación de poder ser afectado psíquica o emocionalmente en un sentido dañino para el normal desarrollo de su sexualidad. A la luz del informe en derecho elaborado por los catorce profesores de derecho penal, la cita de ambos en el considerando $14^{\circ}$ representa un malentendido, cuando no una tergiversación. 
con personas de género masculino, con tal que no consistan en ser él objeto de acceso carnal. Sin embargo, según la interpretación que el voto de mayoría hace del Art. $365 \mathrm{CP}$ la ley desconocería radicalmente la autonomía del menor púber, rebajándolo a la condición de impúber, cuando se trata de realizar una acción sexual específica, el coito anal en el rol pasivo.

Tanto el requerimiento como el informe elaborado por los catorce profesores de derecho penal hacen de este aspecto problemático del Art. 365 la razón central de su impugnación como un precepto legal inconstitucional. El voto disidente acoge esta consideración sosteniendo que la protección de las personas menores de edad debe hacerse respetando su autonomía (cons. $24^{\circ}$ a $28^{\circ}$ ). La tesis del informe en derecho y el voto disidente es además compartida por el Comité sobre Derechos del Niño de Naciones Unidas. En su informe de 2 de febrero de 2007 se expresa:

$[\mathrm{P}]$ reocupa al Comité que las relaciones homosexuales, inclusive entre personas menores de 18 años de edad, se sigan penalizando, lo que supone una discriminación sobre la base de la preferencia sexual ${ }^{14}$.

El voto de mayoría, sin embargo, es ciego a esta consideración. Ni siquiera se plantea la pregunta por la justificación de la afectación de la igualdad y la libertad del menor interesado en participar en una relación sexual que incluya el coito. Sólo considera la cuestión como una afectación de la igualdad y la libertad de la persona que accede carnalmente al menor, justificada por la protección del menor.

Esta ceguera pretende explicarse como una asunción del principio del interés superior del niño, consagrado por el Art. 3.1 de la Convención de Derechos del Niño, en calidad de razón suficiente para justificar un trato paternalista duro ${ }^{15}$. Esto constituye un error. Ya sea

${ }^{14}$ Comité de Derechos del Niño, $44^{\circ}$ período de sesiones, Examen de los informes presentados por los estados partes con arreglo al Artículo 44 de la Convención, Observaciones finales: Chile (CRC/C/CHL/CO/3), párrafo 29. El informe en derecho (punto 6.3) y el voto disidente (cons. $27^{\circ}$ ) se hacen cargo de esta opinión; el voto de mayoría la ignora.

${ }^{15} \mathrm{La}$ aplicación de la distinción entre paternalismo duro (hard paternalism) y suave (soft) al trato a menores de edad exige ser contextualizada, pues en abstracto la justificación del trato paternalista por consideración a la minoría de edad es propia del paternalismo suave (Joel Feinberg, The Moral Limits of 
en virtud de una interpretación del Art. 3.1 o bien en virtud de su aplicación en conjunto con el Art. 12 de la convención, es opinión unánime en la jurisprudencia y doctrina que el derecho internacional de los derechos humanos exige que el Estado tome en consideración la voluntad manifiesta de las personas menores de edad y respete el núcleo de autonomía personal garantizado por sus derechos a la libertad de expresión (Art. 13) y de pensamiento (Art. 14), así como su derecho a la vida privada (Art. 16). El paternalismo justificado respecto de los niños supone la consideración de los mismos como sujetos de derecho, en transición desde la incapacidad hacia la plena capacidad de ejercicio, en un proceso de desarrollo progresivo de su autonomía que por lo mismo debe ser progresivamente reconocida por el Estado.

No se necesita desplegar un gran aparato bibliográfico para demostrar la afirmación anterior ${ }^{16}$. Basta con recurrir a las mismas fuentes citadas por el voto de mayoría ${ }^{17}$.

El voto alude a la sentencia C-318/03 de la Corte Constitucional de Colombia, de 24 de abril de 2003, cuyo considerando 3.1 ofrece

Criminal Law, Vol. 3: Harm to Self, 1989, p. 12-16). En este contexto, el paternalismo duro implica considerar absolutamente irrelevante la voluntad del menor y el paternalismo suave considerarla irrelevante sólo en circunstancias de asimetría intensificada, i.e. cuando el menor es impúber, o cuando el menor púber es objeto de abuso en un sentido especial, distinto de la coerción o aprovechamiento de la incapacidad que caracterizan al abuso por regla general.

${ }^{16}$ Para un tratamiento ilustrativo, Miguel Cillero Bruñol, "El Interés Superior del Niño en el Marco de la Convención Internacional sobre los Derechos del Niño", disponible en: http://www.iin.oea.org/iin/cad/sim/pdf/mod1/ Texto\%208.pdf (última visita, 28 de mayo de 2011); Jaime Couso Salas, "El Niño como Sujeto de Derechos y la Nueva Justicia de Familia. Interés Superior del Niño, Autonomía Progresiva y Derecho a Ser Oído”, 2006, pp. 145166, disponible en: http://www.jurisprudenciainfancia.udp.cl/wp/wp-content/ uploads/2009/08/jaime-couso.pdf (última visita, 28 de mayo de 2011).

17 La excepción se encuentra en Gloria Baeza Concha, "El Interés Superior del Niño: Derecho de Rango Constitucional, su Recepción en la Legislación Nacional y Aplicación en la Jurisprudencia”, 2001, pp. 355-362. Esta autora, profesora de Derecho de Menores de la Pontificia Universidad Católica de Chile, entiende al principio del interés superior como una proyección del criterio paternalista tradicional. Con todo, incluso bajo ese error de comprensión la autora cita laudatoriamente una sentencia de la Corte de Apelaciones de San Miguel, de 18 de marzo de 1989, por haber reconocido como base de una decisión sobre tuición "la conveniencia y el interés de las menores, en armonía con los sentimientos y anhelos exteriorizados por ellas, considerando que las niñas son los sujetos y principales beneficiarios del Derecho de Menores" (p. 361). 
entre otras razones justificatorias de la protección que la constitución colombiana ordena dispensar a los menores de edad "su indefensión o vulnerabilidad, por causa del proceso de desarrollo de sus facultades y atributos personales, en su necesaria relación con el entorno, tanto natural como social"18. El voto omite mencionar, sin embargo, que se trata de una sentencia recaída en un procedimiento de control abstracto de constitucionalidad de la Ley 765 de 2002, que aprobó el Protocolo Facultativo de la Convención sobre los Derechos del Niño relativo a la venta de niños, la prostitución infantil y la utilización de los niños en la pornografía (2000). En su contexto, por lo tanto, la finalidad de protección aludida por la Corte Constitucional de Colombia justifica la prohibición de conductas constitutivas de explotación sexual, secuestro, venta o trata de menores de edad, que los Arts. 34 y 35 de la Convención sobre Derechos del Niño ordenan impedir a los estados parte. En ningún caso la Corte deduce de ese fin de protección la legitimidad de una prohibición de acciones sexuales consentidas por un joven mayor de 14 años, ámbito de acción respecto del cual el código penal de Colombia consagra una de las regulaciones más liberales —si no la más liberal- que ofrece el derecho comparado ${ }^{19}$.

El voto de mayoría menciona también la opinión consultiva OC17/2002 de la Corte Interamericana de Derechos Humanos, de 28 de agosto de 2002, sobre la condición jurídica y los derechos humanos del niño, para afirmar que el interés superior del niño justifica "la necesidad de que le sea dada una protección especial, en vista de su falta de madurez física y mental, debilidad o inexperiencia"20. Esto no es más

${ }^{18}$ Disponible en http://www.icbf.gov.co/transparencia/derechobienestar/ cc_sc_nf/c-318_2003.html. El pasaje se encuentra transcrito en el considerando $30^{\circ}$, párrafo primero del voto de mayoría.

${ }^{19}$ Los Arts. 205 a 210 del Código Penal de Colombia, según Ley 599 de 24 de julio de 2000, distinguen entre víctimas menores de 14 años y víctimas mayores de edad; respecto de estas últimas, sólo se prohíbe penalmente las acciones gravemente abusivas. No existe, por lo tanto, una protección penal especial para personas menores de 18 pero mayores de 14 años. Por otra parte, ninguna de las prohibiciones penales efectúa una diferenciación atendiendo al género u orientación sexual de la víctima o del autor del delito.

${ }^{20}$ Considerando $28^{\circ}$, conteniendo la siguiente referencia "OC-17/02 de 28 de agosto de 2002”. En la opinión de la Corte, el pasaje más parecido al texto que el voto de mayoría le atribuye se encuentra en su considerando 60, donde después de citar el preámbulo de la Convención sobre los Derechos del Niño y el Art. 19 de la Convención Americana de Derechos Humanos, se afirma: 
que el principio general de protección de la infancia y la juventud: en ninguna parte de su opinión la Corte Interamericana afirma un principio de paternalismo duro. Por el contrario, la Corte advierte que existen distinciones entre niños y menores de edad, aunque para los fines perseguidos por la opinión no es necesario hacerlas (cons. 40), insiste en que los niños, aun los incapaces, deben ser considerados sujetos de derecho (cons. 41), observa que la protección de los niños en los instrumentos internacionales tiene como objetivo último el desarrollo armonioso de la personalidad de aquéllos y el disfrute de los derechos que les han sido reconocidos (cons. 53) y acepta la legitimidad de la diferencia de trato entre menores y mayores de edad con tal que ellas sirvan al propósito de permitir el cabal ejercicio de los derechos reconocidos al niño, posean una justificación objetiva y tengan como objeto único el ejercicio de los derechos establecidos en la Convención Americana de Derechos Humanos (cons. 55). En este contexto, la Corte entiende al principio del interés superior del niño como subordinado a la finalidad de asegurar la efectiva realización de todos los derechos del niño, propiciando su desarrollo, con pleno aprovechamiento de sus potencialidades (cons. 56 y 59 ).

Esta comprensión de la opinión consultiva de la Corte, junto con su jurisprudencia, es compartida decididamente por Gonzalo Aguilar Cavallo, a quien el voto de mayoría también cita en pretendido apoyo de su paternalismo duro ${ }^{21}$. El autor señala que de los pronunciamientos de la Corte Interamericana "se pueden desprender un conjunto de criterios o elementos componentes del principio del interés superior del niño en donde resaltan la consideración de los derechos humanos de los niños, la participación del niño, niña o adolescente y la valoración del proyecto de vida del niño" 22 , y concluye afirmando que tomar en serio el principio del interés superior del niño exige considerar "el derecho

"En ambos casos, la necesidad de adoptar esas medidas o cuidados proviene de la situación específica en la que se encuentran los niños, tomando en cuenta su debilidad, inmadurez o inexperiencia." Vale la pena notar la diferencia de redacción: ya en su tenor literal es manifiesto que la opinión de la Corte no implica - como pretende el voto de mayoría - que todos los menores de 18 años sean por definición débiles, inmaduros o inexpertos, tal que se haga necesario inhibirlos de realizar su voluntad.

${ }^{21}$ Considerando $29^{\circ}$, párrafo tercero.

22 Gonzalo Aguilar Cavallo, "El Principio del Interés Superior del Niño y la Corte Interamericana de Derechos Humanos", 2008, pp. 223-247, 244. 
del niño a desarrollarse plenamente en un ambiente que promueva sus propios derechos y que ampare su propio proyecto de vida, y, sobre todo, que haga realidad su derecho humano a la participación en las decisiones que lo afecten"23.

Finalmente, el voto de mayoría concluye con la siguiente cita en pretendido apoyo a su tesis:

Conforme señala Miguel Viveros Vergara, cuando se trata del interés superior del niño, lo prudente y razonable según un buen padre de familia o las buenas intenciones no son suficientes ${ }^{24}$.

La cita es tendenciosa. No sólo porque de esas aseveraciones no se concluye la procedencia de un paternalismo duro, sino porque su sentido en el contexto de la obra es precisamente el contrario: servir como razones para impugnar ese paternalismo. Inmediatamente después del punto seguido con que termina la cita del tribunal, el autor citado suscribe la declaración más enfática que existe en nuestro medio en contra de la concepción paternalista dura del principio del interés superior del niño. En sus propias palabras:

Como ya se ha venido destacando en el medio, "[...] debe abandonarse cualquier interpretación paternalista-autoritaria del interés superior; por el contrario, se debe armonizar la utilización del interés superior del niño con una concepción de los derechos humanos como facultades que permiten oponerse a los abusos del poder y superan el paternalismo que ha sido tradicional para regular los temas relativos a la infancia $[\ldots]^{\prime 25}$.

Esta concepción del menor de edad como un sujeto dotado de una autonomía progresiva que debe ser también progresivamente reconocida por el Estado se contrapone diametralmente a la descripción del menor como víctima necesitada de protección con que el voto de mayoría encabeza su análisis del fin de protección que perseguiría el Art 365 CP:

${ }^{23}$ Ibídem, p. 245.

${ }^{24}$ Considerando $29^{\circ}$, párrafo cuarto (las cursivas son de la sentencia).

25 Miguel Viveros Vergara, "La Legislación y el Interés Superior del Niño", 1999, pp. 54-58, 55. El pasaje entrecomillado por Vergara proviene del artículo de Miguel Cillero citado en la nota 16. 
[D] esde la doctrina especializada se ha sostenido que "el adolescente es, a su propia manera, inocente e inexperto, a pesar de la madurez de sus capacidades y apetitos. Su curiosidad sobre el sexo es avasalladora, pero aún no están claros sobre los significados sexuales y los códigos de propiedad sexual. Tienen menos control de sus impulsos y también se encuentran menos claros sobre sus orientaciones sexuales, además de ser vagos en cuanto a su responsabilidad sexual [...] El compañero adolescente es, en algunos sentidos, él mismo un niño $[\ldots]^{\prime 26}$.

La cita no es honesta. La "doctrina especializada" a la que alude el voto de mayoría no es doctrina del derecho internacional de los derechos humanos ni del derecho penal, ni siquiera es doctrina jurídica, sino un estudio sociológico de una muestra de estudiantes universitarios ingleses que se refieren a sus experiencias sexuales infantiles y juveniles, publicado en $1979^{27}$. En ninguna parte de ese estudio se sostiene que los menores de 18 años deban ser considerados como incompetentes para consentir actos homosexuales. Es más, la tesis central del libro, basada en los resultados que arrojó el estudio de la muestra, es que el factor más importante asociado al trauma del menor es el uso de la fuerza en su contra ${ }^{28}$. O sea, precisamente el factor que el legislador no toma en cuenta al describir el delito en el Art. 365. La tergiversación del texto es tal, que el pasaje transcrito ni siquiera describe al adolescente que es víctima de un abuso sexual. Como se expresa al final del pasaje, se trata de una descripción del "compañero adolescente", es decir, del adolescente que es autor del delito ${ }^{29}$.

${ }^{26}$ Considerando $28^{\circ}$, párrafo tercero.

27 David Finkelhor, Sexually Victimized Children, 1979. La cita es a la edición en castellano: El Abuso Sexual al Menor. Causas, Consecuencias y Tratamiento Psicosocial, 1980. El fallo cita la página 114 del libro, pero el pasaje transcrito se encuentra en su página 116.

${ }^{28}$ Ibídem, p. 202-203.

${ }^{29}$ El pasaje se encuentra dentro del capítulo 5 del texto, dedicado a los "Compañeros de mayor edad", que refuta la imagen tradicional del abusador como "un hombre viejo frustrado sexualmente que rondaba por los parques públicos o los patios escolares buscando atraer algún jovencito inocente" (p. 106). El resultado de la muestra confirma otros estudios, en el sentido de que en la mayoría de los casos el abusador es una persona conocida del menor y, además, joven. El capítulo compara primero al abusador masculino (claramente predominante) con la abusadora femenina, y luego al abusador adolescente con el 
6. La pretensión de justificar un paternalismo duro en el principio del interés superior del niño es una parte del argumento del Tribunal Constitucional. La otra parte se refiere al daño respecto del cual se lo pretende proteger contra su voluntad. ¿En qué consisten esos "efectos, incluso físicos" que irrogan "daños o perjuicios al desarrollo psicosocial" a los que alude el voto de mayoría?

La sentencia nunca responde derechamente esa cuestión, sino que se refiere al punto incidentalmente en tres considerandos:

(i) describe el acto como una conducta que deja al menor "en una posición desmedrada", por lo que constituye un "episodio [...] que lo determina o condiciona, de alguna manera relevante, al momento de tener que definir, con plena libertad, su propia identidad sexual" (cons. 28 $8^{\circ}$ );

(ii) afirma que el hecho de que el menor juegue un papel pasivo constituye "un tipo de relación lesiva de su dignidad como persona, afincada en la inmadurez de su desarrollo psíquico y sexual" (cons. $31^{\circ}$ );

(iii) sostiene que la penetración anal produce un "impacto [...] en el desarrollo psicosocial del menor varón $[. .$.$] que no podría predicarse,$ en los mismos términos, de una relación entre mujeres en las mismas condiciones" (cons. $33^{\circ}$ ).

Como se puede ver, el voto de mayoría oscila entre considerar a la penetración anal como un acto intrínsecamente degradante para quien recibe la penetración y considerarlo como un acto inherentemente dañino (o peligroso) para el desarrollo psíquico de la persona que recibe la penetración, cuando esa persona es menor de 18 años. La primera consideración obviamente hace suya una representación cultural arraigada desde la antigüedad, conforme a la cual el rol pasivo en el coito es incompatible con la masculinidad ${ }^{30}$. Considerar sin embargo que en este contexto ésa es una razón válida para que la ley lo prohíba es algo muy distinto. Implica subordinar el reconocimiento de la dignidad humana a

abusador adulto. A este segundo contexto pertenece el pasaje citado, en el cual se aduce razones que hacen discutible la equiparación del abusador adolescente al abusador adulto y por ello justifican su estudio diferenciado en la muestra. Lo más interesante se encuentra en el resultado, que arroja una diferencia entre niños y niñas. Para éstas, la experiencia con el compañero adolescente resulta por lo general tan traumática como la experiencia con el compañero adulto. Para los niños, en cambio, la experiencia con el compañero adolescente - por lo tanto, experiencia homosexual - es marcadamente distinta, y muchas veces incluso es evaluada positivamente (p. 118).

30 Para un vistazo documentado, A. Williams Craig, Roman Homosexuality, 1999, especialmente pp. 17 s., 125 s. 
la conformidad con un estereotipo. Si eso no es discriminación, entonces nada lo es. Puede que los suscriptores del voto de mayoría compartan sinceramente ese prejuicio, pero su decisión debe basarse en razones constitucionales y no en la expresión de sus estados mentales.

La segunda consideración es un enunciado de hecho, cuya verosimilitud debe ser acreditada. El voto de mayoría ni siquiera se preocupa en aducir algún tipo de evidencia, bastándoles a quienes lo suscriben su certeza doméstica. Eso, en circunstancias que la "doctrina especializada" sobre los abusos sexuales contra menores que ellos dicen seguir desmiente esa afirmación. Según los resultados de ese estudio, el tipo de acción sexual realizada con el menor de edad no tiene una relación directa con la magnitud del trauma experimentado ${ }^{31}$.

Lo más notable del voto de mayoría, sin embargo, se encuentra en la indefinición del resultado perjudicial para el menor. ¿Cuál es ese daño? El intérprete de la sentencia tiene dos opciones: concluir que el daño es la misma homosexualidad o constatar que no hay descripción alguna del daño cuya evitación justificaría la prohibición. O sea, o bien el Tribunal Constitucional incurre en discriminación por razón de orientación sexual, o bien valida una prohibición penal que carece de fin de protección.

7. Nada de esto es nuevo en el derecho comparado, ni la decisión del legislador chileno en 1999 ni su falaz validación por el Tribunal Constitucional. En los países europeos que durante el siglo xix conservaron la prohibición general de la homosexualidad recibida del derecho canónico y medieval, como el Reino Unido, Alemania y Austria, dicha prohibición fue sustituida durante la segunda mitad del siglo xx por una prohibición de contacto homosexual con jóvenes ${ }^{32}$. Eso fue lo que hizo

31 "Los niños que han estado involucrados en un coito no parecen sentir una mayor negatividad hacia su experiencia que aquellos que solamente fueron tocados en sus genitales. El coito ciertamente no destacaba como un factor particularmente negativo en la experiencia, tanto para los niños como para las niñas, y el simple frotamiento de los genitales era tan negativo como cualquier otro tipo de contacto físico real" (Finkelhor, 1979, p. 148). Recuérdese que según el estudio, la variable más importante como causa del trauma es la fuerza ejercida sobre el menor (supra, nota 29).

32 En el Reino Unido la sección 61 de la Ley de Ofensas contra la Persona de 1861 fue sustituida por la Ley de Ofensas Sexuales de 1967. En Alemania, el $\S 175$ del código penal alemán de 1870 fue sustituido por una nueva disposición en el mismo parágrafo en 1969. En Austria, el § 129 del código penal de 1853 fue sustituido por una nueva disposición en el mismo parágrafo en 1971, correspondiendo la disposición al § 209 entre 1975 y 2002. 
en Chile la Ley 19.617, con 30 años de retraso respecto de Europa. La facilidad con que se aceptó en ese entonces que la protección de la juventud brindaba justificación suficiente para mantener ese residuo de la prohibición demostraba naturalmente la fuerza de la moral social sexual heredada: la ley penal podía tolerar divergencias por parte de adultos pero afirmaba esa moral sexual respecto de los menores de edad. El tránsito desde un reclamo de libertad y privacidad hacia un reclamo de reconocimiento igualitario que caracteriza la evolución del discurso legitimatorio de la diversidad sexual en occidente trajo consigo el descrédito de esa justificación como una consideración discriminatoria ${ }^{33}$.

En el caso de Alemania, el trato discriminatorio de la homosexualidad juvenil respecto de la heterosexualidad fue eliminado a iniciativa del propio legislador, en el contexto de los cambios legales requeridos por la reunificación. La $29^{\mathrm{a}}$ ley de modificación del derecho penal, de 31 de mayo de 1994, suprimió el $\S 175$ del código penal alemán, referido desde 1969 a la prohibición de la homosexualidad juvenil, y modificó su $\S 182$, hasta entonces referido a la seducción de una muchacha. En su lugar, estableció un delito de abuso sexual de jóvenes - mayores de 14 pero menores de 16 años-, mediante aprovechamiento de una situación de necesidad, mediante contraprestación de dinero o mediante aprovechamiento de la falta de capacidad de autodeterminación sexual. Desde 1994 el código penal alemán no establece distinciones atendiendo al carácter heterosexual u homosexual de las acciones realizadas con mayores o menores de edad ${ }^{34}$.

En el caso de Inglaterra y Austria, las modificaciones legales fueron exigidas por decisiones judiciales que revisaron decisiones previas, inicialmente validatorias de la prohibición de la homosexualidad

${ }^{33}$ Para un examen ilustrativo de ese tránsito, concretado en la oposición entre privacidad (libertad) y publicidad (reconocimiento), Kenji Yoshino, "El Derecho a la Publicidad", 1998, pp. 43-55; también, Antonio Bascuñán, "La Afirmación de la Diversidad", 2007, pp. 63-70. En el derecho penal, junto al tratamiento de la iniciación sexual, el aspecto más sensible a la discriminación por razón de orientación sexual una vez derogada la prohibición general de la homosexualidad es la expresión pública de la sexualidad. La tolerancia que el sistema punitivo demuestra frente a la divergencia privada respecto de la moral social sexual no se extiende a su expresión en los espacios públicos; la calificación de lo ofensivo - la obscenidad, el escándalo_-, siempre depende de la expectativa cultural dominante.

34 Maurach, Reinhardt, Friedrich-Christian Schroeder y Manfred Maiwald, Strafrecht-Besonderer Teil, 2003, Tomo I, p. 212 s. 
juvenil. En Dudgeon v. The United Kingdom ${ }^{35}$ la Corte Europea de Derechos Humanos, al mismo tiempo que declaró a la prohibición general de la homosexualidad - a ese entonces todavía vigente en Irlanda del Norte - como incompatible con el derecho a la vida privada, reconoció a los Estados legítima competencia para establecer una regla especial relativa al consentimiento en actos homosexuales, más exigente que la regla relativa al consentimiento en actos heterosexuales ${ }^{36}$. Ese criterio ya había sido aplicado por la Comisión Europea de Derechos Humanos para validar la prohibición inglesa de la homosexualidad juvenil ${ }^{37}$ y volvió a serlo en relación con la misma prohibición contemplada en el código penal austríaco de $1975^{38}$. Sin embargo, en su informe recaído en el caso Sutherland v. The United Kingdom ${ }^{39}$, la Comisión consideró que las razones ofrecidas por el gobierno británico como fundamento de la prohibición de realizar acciones homosexuales con menores de 18 años no ofrecían una justificación razonable y objetiva. Esas razones eran (i) que algunos hombres cuya edad oscila entre los 16 y los 18 años no tienen definida su orientación sexual, por lo que son vulnerables a acciones que pueden posteriormente perjudicarlos, y (ii) que la sociedad está legitimada para expresar su desaprobación de la conducta homosexual y su preferencia de que los niños sigan un modo de vida heterosexual. En opinión de la Comisión:

[...] ninguno de los argumentos ofrece una justificación razonable y objetiva para mantener una edad diferente para el consentimiento de actos homosexuales y heterosexuales o que mantener esa diferenciación de edad sea proporcionada a algún propósito legítimo al cual sirva. En lo que respecta al primer argumento, se concedió en los debates parlamentarios que la actual opinión médica considera que la orientación sexual se encuentra fijada en ambos sexos ya a la edad de 16 años y que los hombres de edad entre 16 y 21 años no se encuentran en una especial necesidad de protección frente al riesgo de ser "reclutados" en la homosexualidad. [...].

En lo que se refiere al fundamento de la segunda razón - la alegada facultad de la sociedad para indicar desapro-

\footnotetext{
${ }^{35}$ Sentencia de 22 de octubre de 1981 ( $\left.N^{\circ} 7525 / 76\right)$.

${ }^{36}$ Considerandos 61 y 62.

${ }^{37}$ X. v. the United Kingdom $\left(\mathrm{N}^{\circ} 7215 / 75\right)$.

${ }^{38}$ W. Z. v. Austria (N०. 17279/90); H.F. v Austria ( $\left.\mathrm{N}^{\circ} 22646 / 93\right)$.

${ }^{39}$ Dictamen de 1 de julio de 1997 (N²5186/94).
} 
bación de la conducta homosexual y su preferencia por un estilo de vida heterosexual-, la Comisión no puede aceptar que esto pudiera en caso alguno constituir una justificación objetiva o razonable para la falta de igualdad del tratamiento bajo la ley penal. Como la Corte observó en su sentencia Dudgeon en el contexto del Artículo 8 (art. 8) de la Convención: "Desincriminación" no implica aprobación, y el temor de que ciertos sectores de la población puedan inferir de la reforma de la legislación conclusiones equivocadas a este respecto no brinda una buena razón parta mantenerla en vigencia con todas sus injustificables características ${ }^{40}$.

El caso Sutherland no fue resuelto por la Corte, en atención a que el Parlamento inglés redujo la edad requerida para el consentimiento del menor a los 16 años mediante una reforma legal que entró en vigor el 8 de enero de $2001^{41}$. La reforma legal de 2001 quedó consolidada en el Reino Unido con la entrada en vigencia de la Ley de Ofensas Sexuales de 2003, uno de cuyos principios fundamentales es la ausencia de toda diferenciación basada en consideraciones de género, sexo u orientación sexual $^{42}$.

En que respecta a Austria, en 1989 el Tribunal Constitucional Austríaco declaró que el $\S 209$ del código penal austríaco de 1974, que penalizaba la relación sexual entre un hombre mayor de 19 años y un hombre menor de 18 pero mayor de 14 años, no era inconstitucional ${ }^{43}$. En 2002, sin embargo, el mismo tribunal declaró inconstitucional dicha disposición, atendiendo a las diferencias injustificables en razón de edad

${ }^{40}$ Sutherland $v$. The United Kingdom ( ${ }^{\circ}$ 25186/94), considerandos 64-65.

${ }^{41}$ Sutherland v. The United Kingdom ( $\mathrm{N}^{\circ}$ 25186/94), sentencia de 27 de marzo de 2001. No obstante, respecto de otro caso de aplicación de la ley inglesa previa a la reforma de 2001 la Corte consideró el año 2004, tal como lo hiciera la Comisión en el caso Sutherland, que la diferencia de edad para el consentimiento de actos homosexuales y heterosexuales constituía una violación del artículo 14 en conexión con el artículo 8, ambos del Convenio Europeo, y ordenó al Reino Unido pagar costas procesales e indemnización de perjuicios al recurrente (B.B. $v$ The United Kingdom, $\mathrm{N}^{\circ} 53769 / 00$, sentencia de 10 de febrero/7 de julio de 2004).

${ }^{42}$ Al respecto, Raimond Card, Sexual Offences: The New Law, 2004, especialmente p. $63 \mathrm{~s}$.

${ }^{43}$ Sentencia de 3 de octubre de 1989 (G227/88, G2/89). 
que resultaban del hecho de exigir la ley no menos de19 años de edad en el autor ${ }^{44}$.

Por razones distintas, siguiendo Sutherland v. The United Kingdom la Corte Europea de Derechos Humanos también impugnó la legitimidad del § 209 del Código Penal austríaco, sosteniendo que violaba el derecho a la igualdad tomado en conjunto con el derecho a la vida privada, en los siguientes términos:

Lo que es decisivo es si había una justificación razonable para que hombres jóvenes en el margen de edad de 14 a 18 años necesitaran protección frente a relaciones sexuales con hombres adultos, mientras que las mujeres jóvenes del mismo margen de edad no necesitaban tal protección frente a hombres o mujeres adultas. En conexión con esto, la Corte reitera que el ámbito del margen de apreciación dejado al estado contratante variará conforme a las circunstancias, la materia y el trasfondo; a este respecto, uno de los factores relevantes puede ser la existencia o no existencia de una base común entre las leyes de los estados contratantes [...].

El Gobierno descansó en la sentencia del Tribunal Constitucional de 3 de octubre de 1989, la que consideró que el artículo 209 del Código Penal era necesario para evitar "una peligrosa presión [...] puesta por experiencias homosexuales sobre el desarrollo sexual de hombres jóvenes". No obstante, este punto de vista ha quedado superado por el debate parlamentario en 1995 sobre una posible derogación de la disposición. Tal como fue correctamente destacado por los reclamantes, la vasta mayoría de los expertos que ofrecieron evidencia en el Parlamento claramente se pronunciaron a favor de una misma edad de consentimiento, encontrando en particular que la orientación sexual se encuentra en la mayor parte de los casos establecida antes de la edad de la pubertad y que la teoría de que los adolescentes masculinos son "reclutados" en la homosexualidad ha quedado por lo tanto des-

${ }^{44}$ Sentencia de 21 de junio de 2002 (G6/02). Tal como lo sostiene el informe en derecho de los catorce profesores de derecho penal en su punto 4, esta consideración del Tribunal Constitucional austríaco es enteramente aplicable al derecho chileno, se estima aplicable al delito del Art. 365 del Código Penal en atención a lo dispuesto por el Art. 4 de la Ley 20.084, sobre responsabilidad de los adolescentes por infracciones a la ley penal, que declara no procesables a los autores menores de 18 años que tienen menos de 2 o 3 años de diferencia con su compañero sexual de menor edad. La consideración no era sin embargo pertinente para el caso concreto (infra, nota 48). 
aprobada. A pesar de su conocimiento de estos cambios en la perspectiva científica al asunto, el Parlamento decidió en noviembre de 1996, esto es, brevemente antes de las condenas de los reclamantes en enero y febrero de 1997, mantener el artículo 209 en el texto legal.

En la medida en que el artículo 209 del Código Penal consagró un prejuicio predispuesto por parte de la mayoría heterosexual contra la minoría homosexual, estas actitudes negativas no pueden por sí mismas ser consideradas por la Corte como justificación suficiente para el tratamiento diferenciado, no más que actitudes negativas similares respecto de aquellos que pertenecen a una diferente raza, origen o color $[\ldots]^{45}$.

El 13 de agosto de 2002, el legislador austríaco introdujo en reemplazo de la disposición invalidada por el Tribunal Constitucional un nuevo $\S 207$ b en el Código Penal, relativo al abuso sexual de menores de edad. Este nuevo artículo consta de tres incisos, en los cuales la ley configura atentados constitutivos de abuso del menor en virtud de las circunstancias que concurren (aprovechamiento de la falta de madurez del menor, superioridad en razón de una mayor edad, aprovechamiento de la situación de necesidad del menor, contraprestación económica). El nuevo precepto no establece diferencias entre las acciones de significación sexual heterosexuales y homosexuales ${ }^{46}$.

Todos estos antecedentes fueron puestos en conocimiento del Tribunal Constitucional chileno. El informe de los catorce profesores de derecho penal los hizo valer y el voto de minoría los reconoció. Pese a ello, el Tribunal decidió reproducir las consideraciones que hoy en día se encuentran obsoletas en Europa. En esto quizás radique su novedad: en la impudicia con que se desentiende de la evolución del derecho comparado. Con auténtica vocación de localismo cisandino, el voto de mayoría asume que puede mantener como consideración no problemática un punto de vista descartado hace diez años por la jurisprudencia de derechos humanos en Europa.

${ }^{45}$ L. and V. v. Austria, 9 de enero de 2003 ( ${ }^{\circ} 39392 / 98$ y 39829/98), 49, 51, 65-66; seguido en Wolfmeyer v. Austria, 26 de mayo de $2005\left(\mathrm{~N}^{\circ}\right.$ $5263 / 03)$.

${ }^{46} \mathrm{La}$ aplicación del $\S 207 \mathrm{~b}$ por los órganos de prosecución penal sí ha mantenido, sin embargo, un sesgo discriminatorio de la homosexualidad masculina. Esa práctica discriminatoria ha sido observada por el Parlamento Europeo, que ha exhortado a Austria a una aplicación libre de discriminación del precepto legal (Resolución acerca de la situación de los derechos fundamentales en la Unión Europea, de 4 de septiembre de 2003, párrafo 79). 
8. El poco tiempo que lleva ejerciendo las atribuciones que le fueran conferidas por la Ley de reforma constitucional 20.050 (Diario Oficial de 26 de agosto de 2005) ha bastado al Tribunal Constitucional para demostrar su particular ineptitud en el tratamiento de los principios constitucionales que definen y limitan el ejercicio de la potestad punitiva del Estado ${ }^{47}$. Con esta sentencia el tribunal se ha superado a sí mismo. Si hubiera que juzgarlo a la luz de la tergiversación que el voto de mayoría hace de sus pretendidas fuentes de apoyo doctrinario, de la displicencia con que elude la cuestión constitucional central planteada por el requerimiento y de la frivolidad con que afirma enunciados que tanto sus fuentes como la jurisprudencia comparada considera refutados, habría que concluir que ya no se trata de una institución inepta sino francamente irrisoria.

En lo que respecta a la discusión acerca de la legitimidad de la represión penal de la homosexualidad juvenil masculina puede sacarse dos conclusiones.

La primera, que queda abierta la interrogante de si un caso futuro en el que sea evidente el interés del propio joven homosexual en realizar el coito anal en un rol pasivo pueda problematizar la regla ante el tribunal como lo que es: una limitación inconstitucional de la autonomía sexual del menor ${ }^{48}$.

${ }^{47}$ El Tribunal Constitucional ha pretendido que la infracción de una garantía del principio de legalidad puede compensarse con la satisfacción de otra (Rol N 486-06, 559-06, 1191-08), ha sostenido que el empleador que no paga las cotizaciones previsionales no es un deudor de una obligación de dinero sino un detentador de cosa de propiedad ajena ( $\mathrm{Rol} \mathrm{N}^{\circ}$ 519-06, 576-06), ha acudido a una definición de Wikipedia para afirmar que un concepto legal no es indeterminado ( $\mathrm{Rol} \mathrm{N} \mathrm{N}^{\circ}$ 549-06), ha sostenido que una presunción legal no altera la carga de la prueba del hecho punible (Rol $\mathrm{N}^{\circ} 739-07$ ), ha exigido respecto de un delito una prueba de peligrosidad concreta sin indicar qué hecho distinto de la acción típica correspondería a esa prueba ( $\left.R o l N^{\circ} 739-07\right)$, ha confundido la proporcionalidad prospectiva (preventiva) con la proporcionalidad retrospectiva (proporcionalidad de culpabilidad) (Rol $\left.N^{\circ} 825-07,829-07\right)$, ha estimado que un acto legislativo inconstitucional por infracción a reglas de competencia puede ser convalidado si su contenido es equivalente al de una disposición previa a la entrada en vigencia de la Constitución (Rol $\left.N^{\circ} 1191-08\right)$ y ha confundido la satisfacción de las reglas legales de imputación subjetiva con el contenido del principio constitucional de culpabilidad ( $\left.\mathrm{Rol} \mathrm{N}^{\circ} 1584-09\right)$.

${ }^{48}$ En este caso se acusaba a una persona que al momento de los hechos tenía 33 años de haber accedido carnalmente a una persona que a ese momento tenía 14 años recién cumplidos. La acusación del Ministerio Público incluía al menor como su primer testigo de cargo y el requerimiento presentado por la Defensoría Penal Pública no adujo la existencia de relación afectiva alguna entre el acusado y el menor. El caso no parecía implicar, en consecuencia, un interés sexual del menor que hubiera sido afectado por la prohibición del Art. 365 y su aplicación en una investigación y juicio penales. Este es un dato importante para distinguir este caso de eventuales casos futuros. 
Como segunda conclusión está el hecho de que ni siquiera la facción más conservadora de la cultura jurídica chilena, atrincherada en el Tribunal Constitucional, se considera habilitada para apelar abiertamente a un discurso condenatorio de la homosexualidad. Es cierto que ese discurso domina la decisión de la mayoría del tribunal, apenas encubierto por consideraciones pseudo-naturalistas. Pero el mismo hecho de ese encubrimiento es significativo. Los tiempos han cambiado. Ya no es el amor sino el prejuicio el que no se atreve a decir su nombre.

\section{REFERENCIAS BIBLIOGRÁFICAS}

Aguilar Cavallo, Gonzalo. "El Principio del Interés Superior del Niño y la Corte Interamericana de Derechos Humanos". $6 \mathrm{~N}^{\mathrm{o}} 1$ Estudios Constitucionales (2008).

Baeza Concha, Gloria. "El Interés Superior del Niño: Derecho de Rango Constitucional, su Recepción en la Legislación Nacional y Aplicación en la Jurisprudencia". 28-2 Revista Chilena de Derecho (2001), p. 355362.

Bascuñán, Antonio. "La Afirmación de la Diversidad". Revista Universidad Diego Portales No 5 (2007).

Boswell, John. Cristianismo, Tolerancia Social y Homosexualidad. Barcelona, Muchnick Editores S.A., 1993.

Card, Raimond. Sexual Offences: The New Law. Bristol: Jordan Publishing Limited, 2004.

Cillero Bruñol, Miguel. "El Interés Superior del Niño en el Marco de la Convención Internacional sobre los Derechos del Niño”. Disponible en: http://www.iin.oea.org/iin/cad/sim/pdf/mod1/Texto\%208.pdf (última visita, 28 de mayo de 2011).

Corte Constitucional de Colombia. Sentencia C-318/03. Disponible en http:// www.icbf.gov.co/transparencia/derechobienestar/cc_sc_nf/c-318_2003. html.

Corte Interamericana de Derechos Humanos. Opinión consultiva OC-17/2002, de 28 de agosto de 2002.

Craig, A. Williams. Roman Homosexuality. Oxford: Oxford University Press, 1999.

Couso Salas, Jaime. "El Niño como Sujeto de Derechos y la Nueva Justicia de Familia. Interés Superior del Niño, Autonomía Progresiva y Derecho a Ser Oído". 3-4 Revista de Derechos del Niño (2006), p. 145-166, disponible en: http://www.jurisprudenciainfancia.udp.cl/wp/wp-content/ uploads/2009/08/jaime-couso.pdf (última visita, 28 de mayo de 2011).

Feinberg, Joel. The Moral Limits of Criminal Law. Volumen 3: Harm to Self. Oxford: Oxford University Press, 1989. 
Finkelhor, David. Sexually Victimized Children. Nueva York: The Free Press, MacMillan Publishing Co., Inc., 1979. Edición en castellano: El Abuso Sexual al Menor. Causas, Consecuencias y Tratamiento Psicosocial. México: Editorial Pax, 1980.

Jordan, Mark D. The Invention of Sodomy in Christian Theology. Chicago: University of Chicago Pres, 1997.

Maurach, Reinhardt; Friedrich-Christian Schroeder y Manfred Maiwald. Strafrecht-Besonderer Teil. Tomo I. C.F. Müller Verlag, 2003.

Viveros Vergara, Miguel. "La Legislación y el Interés Superior del Niño". 64 Revista Universitaria (1999).

Yoshino, Kenji. "El Derecho a la Publicidad". Revista Jurídica de la Universidad de Palermo (1998). 